\title{
The Effect of Acceptance and Commitment Therapy on Improvement of Quality of life in Patients with Multiple Sclerosis
}

Mohammad Barooti

Masters of Counseling, Faculty of Humanities, University of Bojnord, Bojnord, Iran

Ali Akbar Soliemanian

* Associate Professor, Department of Counseling, Faculty of Humanities, University of Bojnord, Bojnord, Iran (Corresponding Author): soliemanian@ gmail.com

Ali Mohamadzadeh Ebrahimi

3. Assistant Professor, Department of Psychology, Faculty of Humanities, University of Bojnord, Bojnord, Iran

Received: 06 January 2019

Accepted: 26 June 2019

DOI: 10.30699/ijhehp.7.3.349

\section{ABSTRACT}

Background and Objective: Multiple Sclerosis (MS) is a chronic disease of the central nervous system, which leads to a decrease in the quality of life due to its physical symptoms and psychological consequences. The purpose of this study was to investigate the effect of acceptance and commitment therapy (ACT) on improving the quality of life of patients with Multiple Sclerosis.

Materials and Methods:The research method was semi-experimental using pretest-posttest and comparing with the control group. The study population consisted of all members of Shirvan city multiple sclerosis association $(N=50)$ in 2017. The sample consisted of 26 volunteers who were randomly assigned to two experimental and control groups (for each group 10 subject). Data gathering instrument was Multiple Sclerosis Quality of Life-54 (MSQOL-54) questionnaire completed by the both groups before and after the intervention. Experiment group participated in 8 sessions of ACT and the control group did not receive any intervention. Covariance analysis method was used to analyze data. All analyzes were performed using SPSS-24.

Results: ACT had a significant effect on improving the quality of life and dimensions of physical and mental health in the experimental group $(p<0.001)$.

Conclusion: ACT improved the quality of life in MS patients; therefore, it is suggested to use ACT to improve the quality of life of patients with MS in addition to medical treatments.

Keywords: Acceptance and Commitment Therapy, Quality of life, Multiple Sclerosis. Paper Type: Research Article.

Citation (Vancouver): Barooti M, Soliemanian AA, Mohamadzadeh Ebrahimi A. The Effect of Acceptance and Commitment Therapy on Improvement of Quality of life in Patients with Multiple Sclerosis. Iran J Health Educ Health Promot. Autumn 2019;7(3): 349-359. [Persian]

- Citation (APA): Barooti M., Soliemanian AA., Mohamadzadeh Ebrahimi A. (Autumn 2019). The Effect of Acceptance and Commitment Therapy on Improvement of Quality of life in Patients with Multiple Sclerosis. Iranian Journal of Health Education \& Health Promotion., 7(3), 349-359 . [Persian] 
تأثير درمان مبتنى بر بذيرش و تعهد بر بهبود كيفيت زندكى بيماران مبتلا به

\section{4}

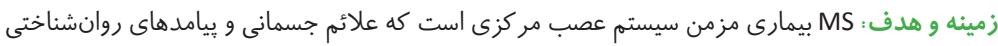

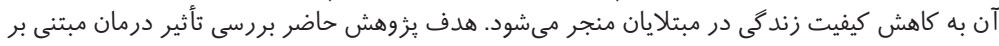

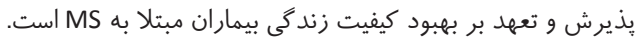

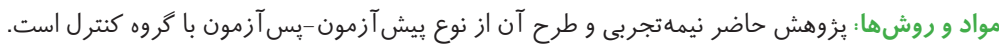

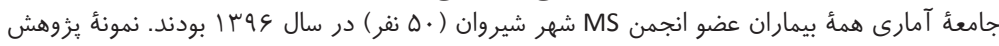

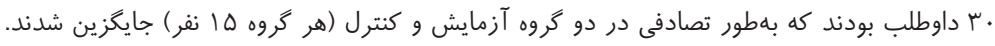

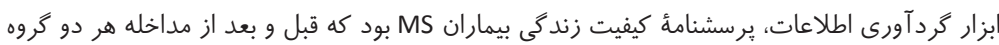

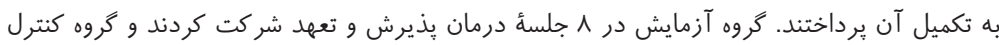

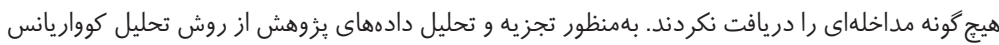

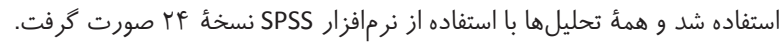

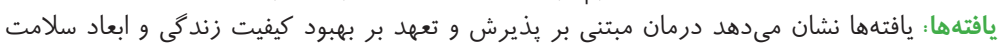

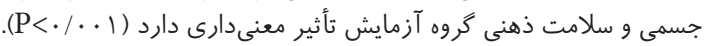

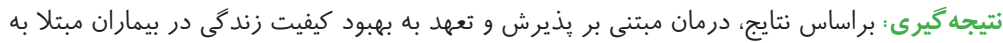

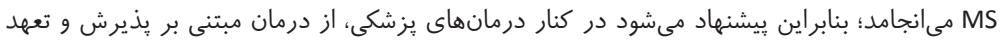

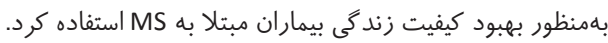

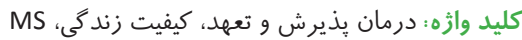
نوع مقاله : مطالعه يزوهشى.

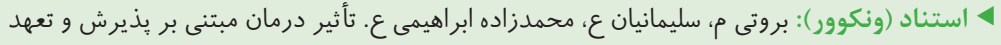

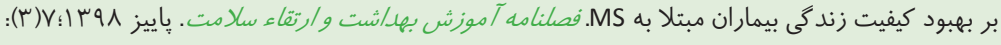

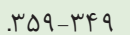

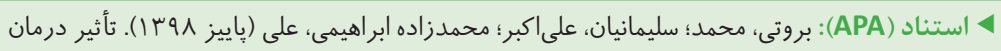

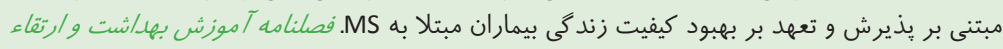

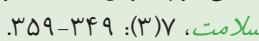

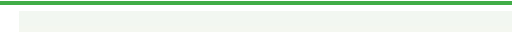

كارشناسى ارشد مشاوره، گروه مشاوره، دانشكدة علوم انسانى، دانشكاه بجنورد، بجنور ده، ايران على اكبر سليمانيان

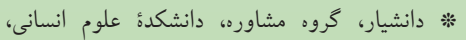
دانشكاه بجنورد، بجنورد، ايران(نو يسنده مسئول): soliemanian@gmail.com

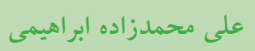

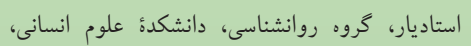
دانشعاه بجنورد، بجنورد، ايران

تاريخ دريافت:

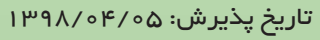


زندگى معيارى جندبعدى و ذهنى است كه خود را در ابعاد جسمى،

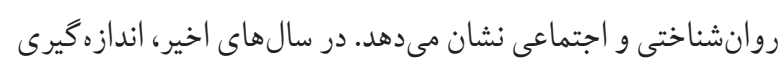

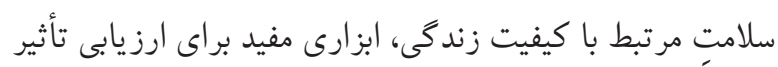

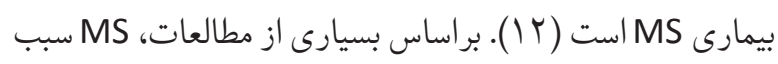

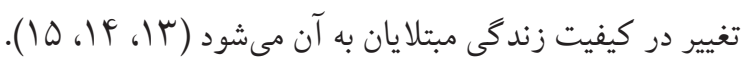

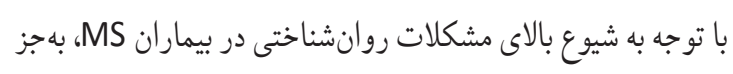

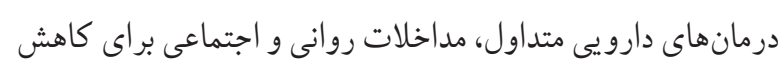

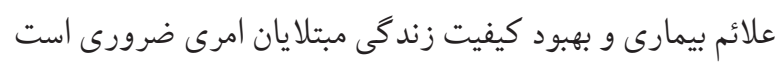

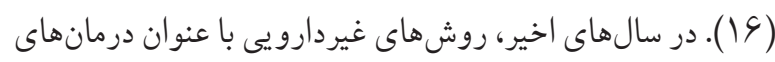

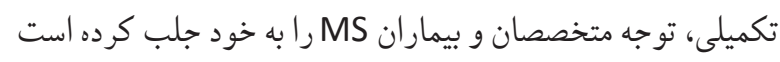

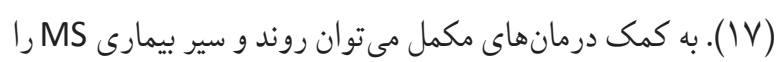

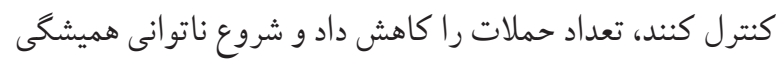

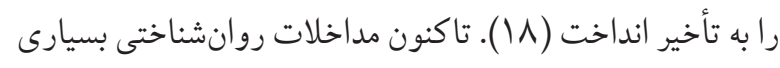

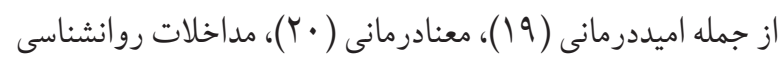

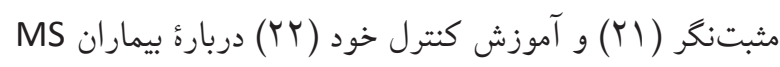
انجام شده كه كيفيت زندكى اين بيماران را ارتقا داده است.

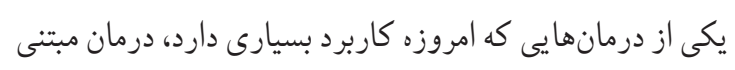

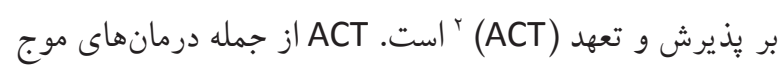

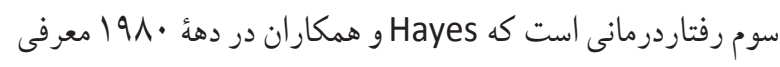

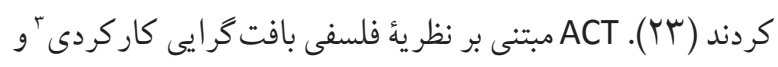

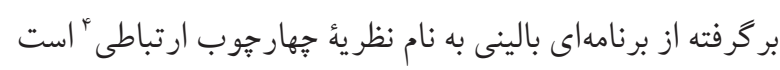

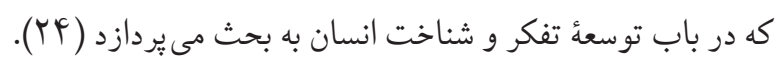

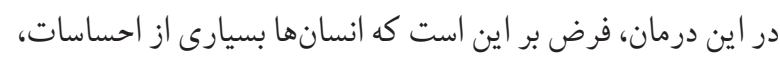

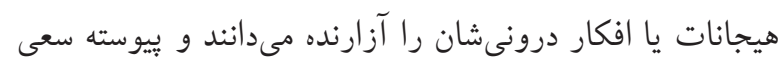
مى كنند اين تجربههاى درونى را تغيير دهند يا از آنها رهايى يابند.

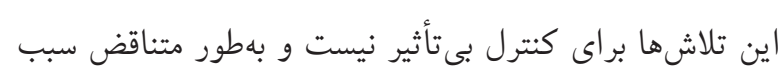
تشديد احساسات، هيجانات و افكارى مىشود كه فرد در ابتدا

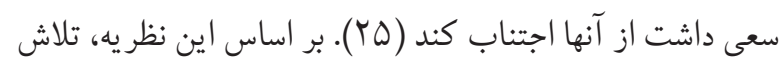

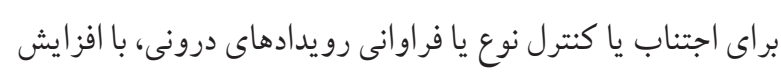

2. Acceptance and Commitment Therapy

3. Functional Contextualism z

4. Relational Framework Theory

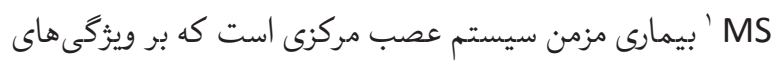

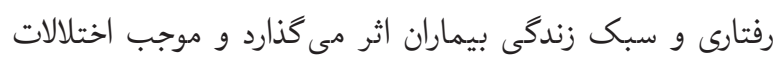

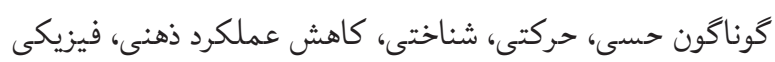

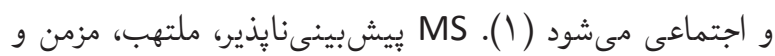

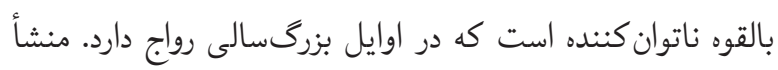

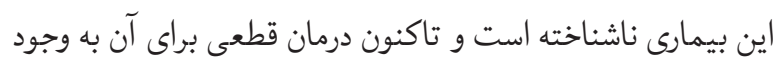

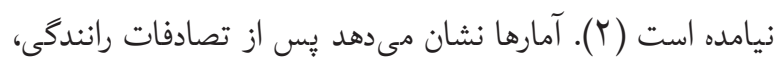

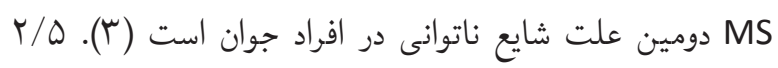
ميليون نفر در جهان به اين بيمارى مبتلا هستند و هرساله م هزار

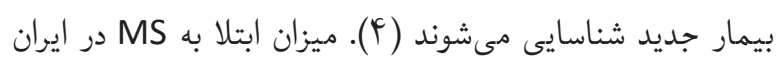

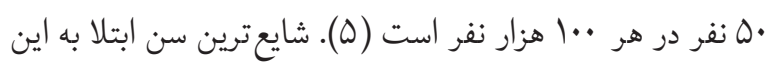

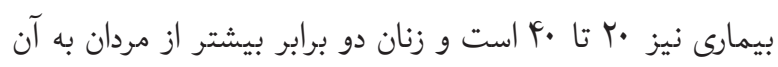

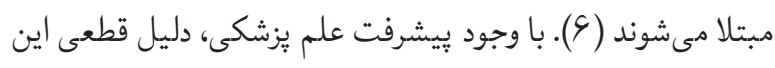

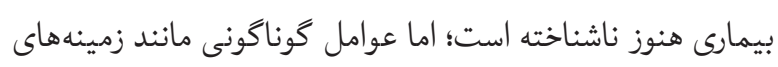
زنتيكى، نقص در سيستم ايمنى، عوامل محيطى مانند عفونتهاى

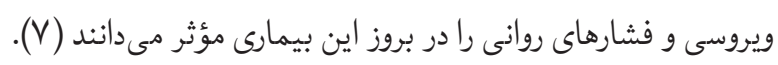

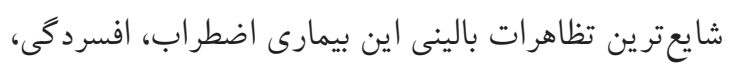

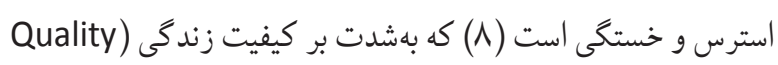
اين بيماران و سطوح ساز كارى روانشناختى با اين بيمارى (of Life

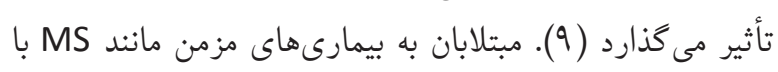
مشكلات زيادى مواجه هستند. اين مشكلات شر كت بيماران را

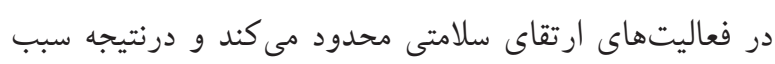
عوارض ثانويه و محدوديت در زندگى مستقل مى شود كه درنهايت

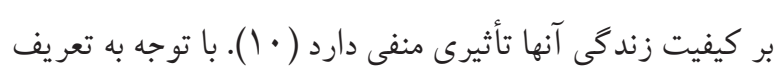

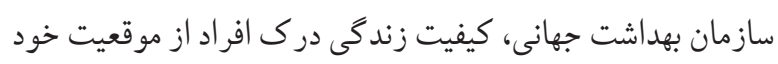
در زندگى به فرهنغ، سيستم ارزشى كه در آن زندكى مي كنند،

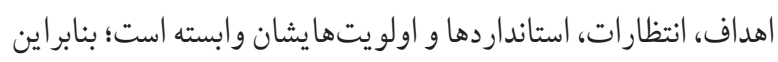

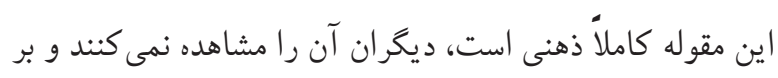
درك فرد از جنبههاى مختلف زندگى استوار است (11). كيفيت

1. Multiple Sclerosis 
ناتوانى مر تبط با درد، رضايت از زندگى، افسردگى، اضطر اب مرتبط

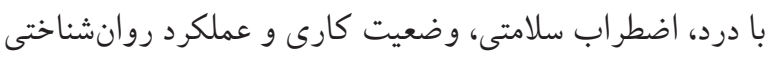

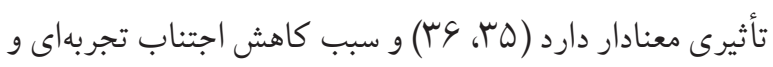

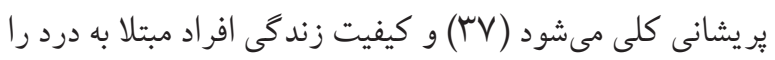

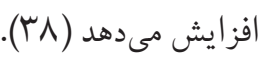
درمجموع MS بيمارى خاص و مزمنى است كه سبب انواع مشكلات روانشناختى مانند افسردگى، اضطر اب، استرس و كاهش كيفيت زندگى مبتلايان مىشود. بهمنظور ارتقاى كيفيت زندكى

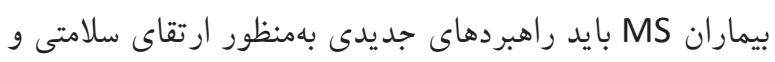

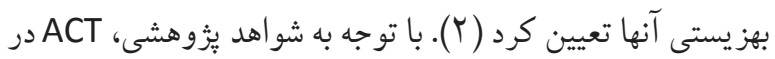
بهبود كار كردهاى روانشناختى، كاهش تجربئ درد، ساز كارى بهتر

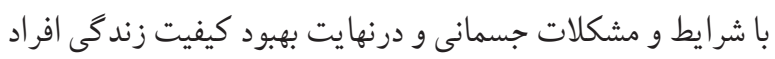

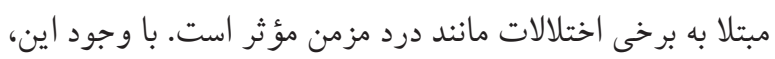

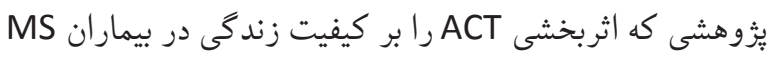

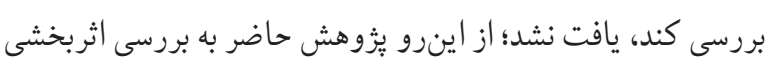

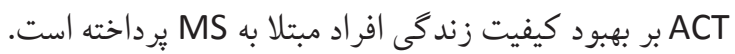

مو ادو و موشها

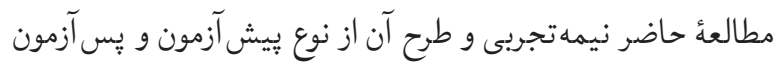

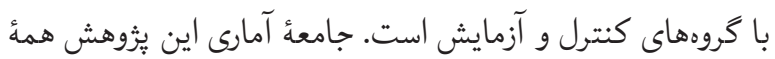
بيماران مبتلا به MS عضو انجمن MS شهر شيروان در سال و9ها هستند. براي انتخاب نمونه از روش نمونه كيرى غيرتصادفى (داوطلبانه) استفاده شد. روند اجراى يُّوهش بدين كونه بود كه پِ إن از دريافت

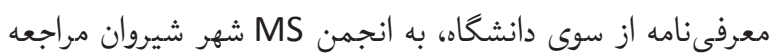

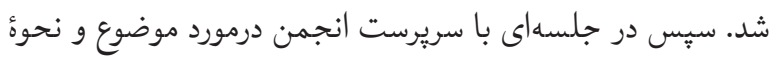

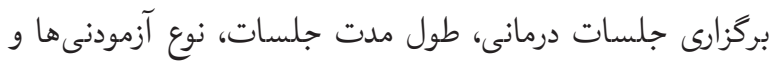

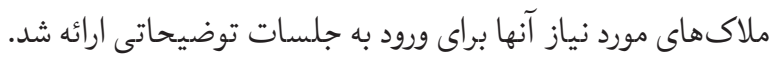

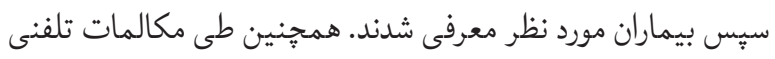

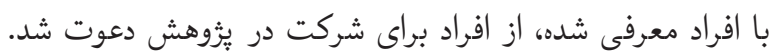

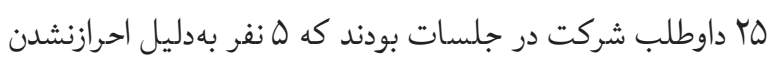

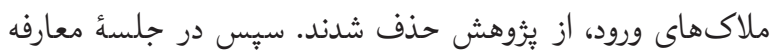

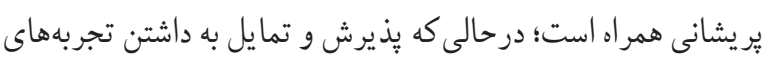

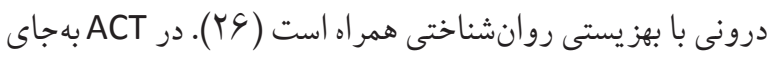

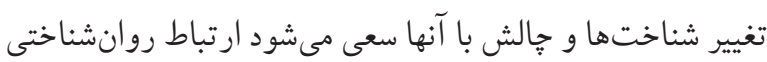
فرد با افكار و احساساتش افزايش يابد؛ يعنى افكار و احساسات

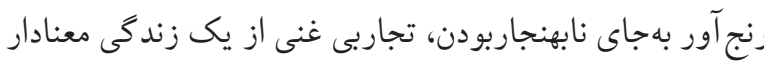

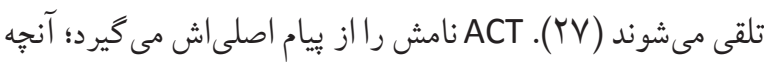

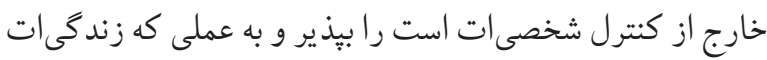

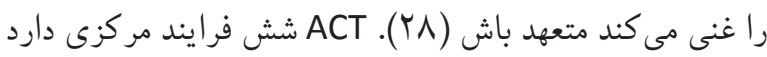

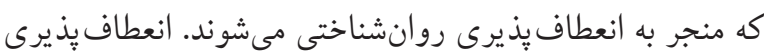

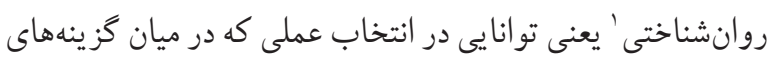

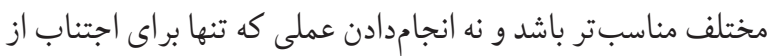

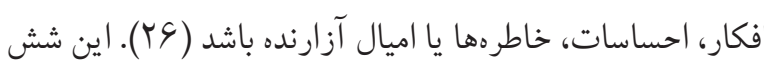

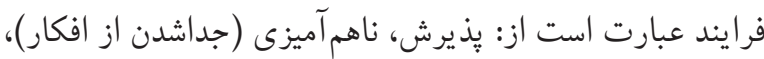

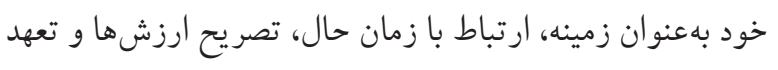
به انجامدادن رفتارهاى ارزشمند (T9). بخش كمى از مطالعات به بررسى تأثير ACT بر برخى يبامدها و

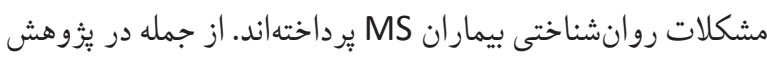

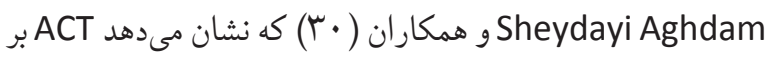
كاهش افكار ناكار آمد و ير يشانى بيمار ان مبتلا به MS مؤثر استر است. همجنين براساس يُّوهشى ديكر، ACT بر اضطراب و افسردكى

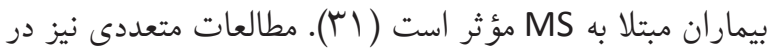
زمينة تأثير ACT بر بيماران مبتلا به درد مزمن انجام شده است.

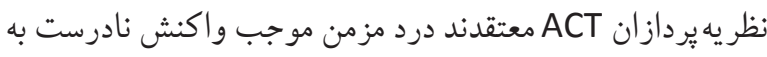

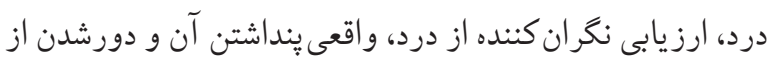

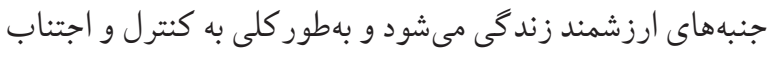

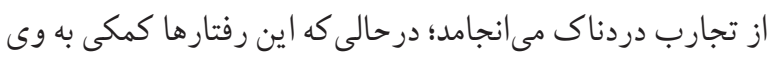

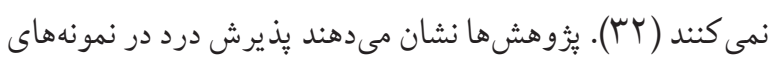

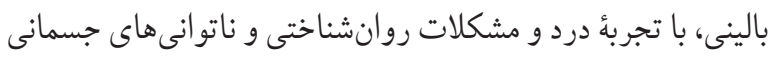
بكمر اتب كمتر و با بهز يستى روانشناختى ارتباط بيشترى دارند (باته،

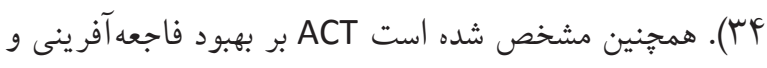




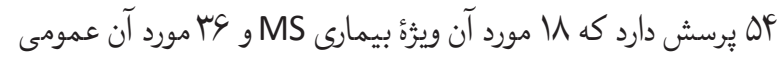
است. F| حيطة مختلف نيز كيفيت زندكى بيماران MS را اندازه كيرى مى كند. حيطههاى fا گانهُ اين يرسشنامه عبارت است از: عملكرد

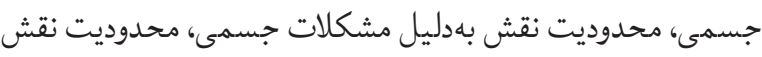
بهدليل مشكلات روحى، عملكرد اجتماعى، تنش سلامتى، عملكرد

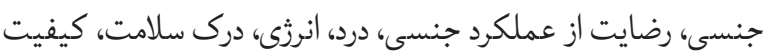

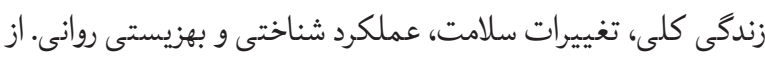
ادغام اين حيطهها، دو حيطةٌ تركيبى سلامت جسمى و سلامت ذهنى

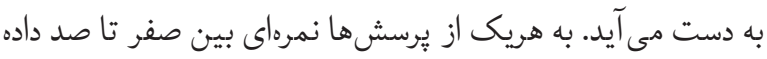

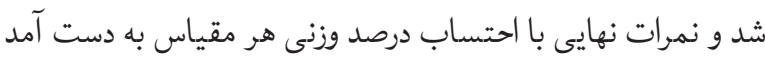

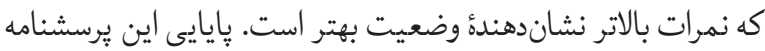

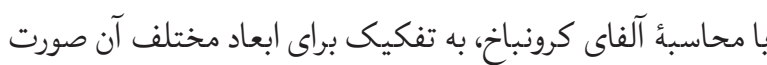

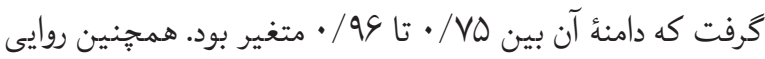

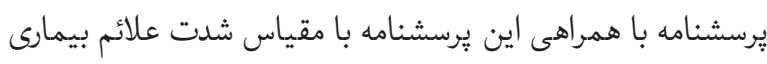
MS و روايى برسشنامه نيز در جامعهُ بيماران MS ايرانى ارزيابى و تأييد

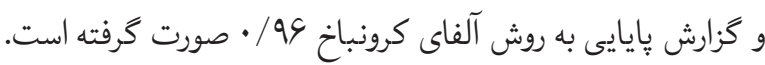

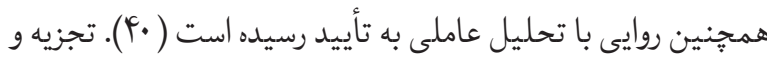

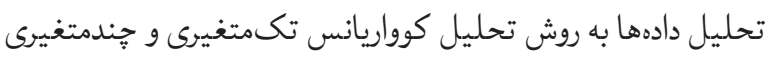

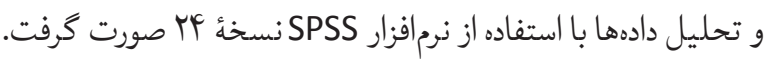

جدول ا. خلاصة محتواى جلسات ACT (

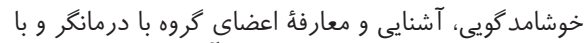

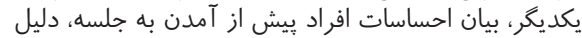

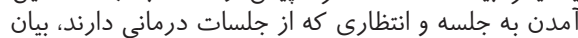

جلسةٔ اول

قوانين و مقررات و معرفى اجمالى درمان و اهداف آن آن آن

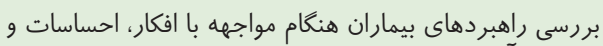

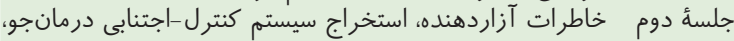
درماندگى خلاق، جمعبندى جلسه و ارائئ تكليف

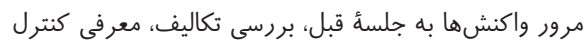

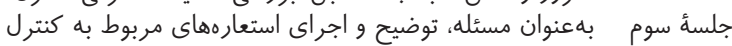
و جمع بندى جلسه واجن

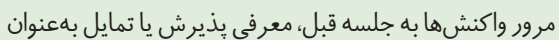

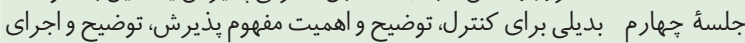

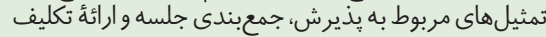

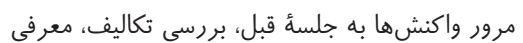

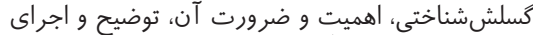
استعارههاى مربوط به آن، جمعبندى جلسه و آرائة تكليف آنراي
كه در آن يُزوهشكر به معرفى خود، اهداف، قوانين، مكان، طول مدت جلسات و... يُرداخت، افراد متقاضى اين طرح ثبتنام شدند.

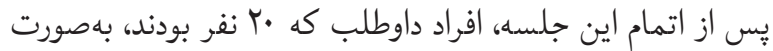

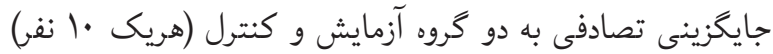
تقسيم شدند. در همين اين جلسه، با تكميل برسشنامه كيفيت

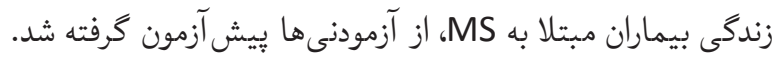

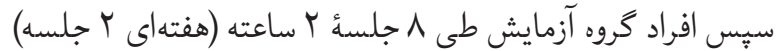
را دريافت كردند، اما گروه كنترل هيج مداخلهاى دريافت نكرد. ACT يك هفته يس از پايان جلسات درمان ACT براى گروه آزمايش،

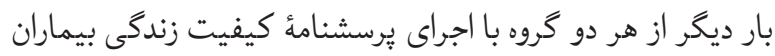
مبتلا به MS بـ آزمون كرفته شد.

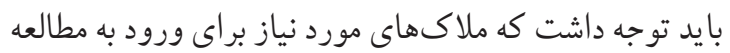

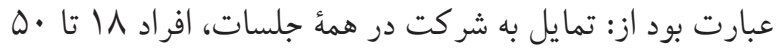
ساله، داشتن مدرك حداقل سوم راهنمايى يا سيكل، بودن در مرحله فرونشانى و نداشتن بيمارى حاد جسمانى ديخر (براساس تشخيص

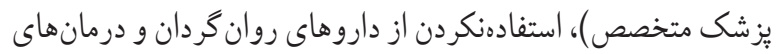

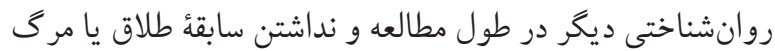

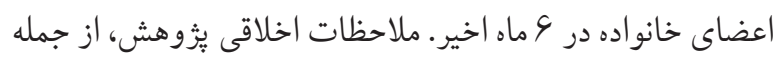
دريافت رضايت آكاهانهُ شر كت كنند گان و محرمانهماندن اطلاعات ملاحطي

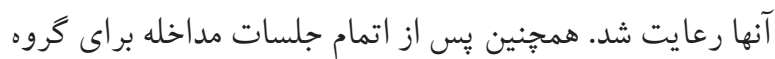

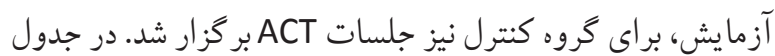
ا خلاصهاى از محتواى جلسات ACT آمده است. ابزار استفادهشه بهمنظور جمع آورى دادههاى يُزوهش نيز به شرح زير است:

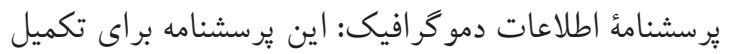
اطلاعات از سوى بثوهشكر تدوين شده است و شامل اطلاعات اوليه

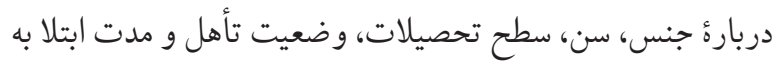

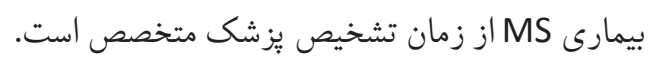

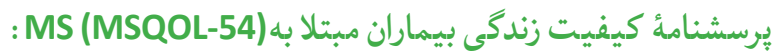

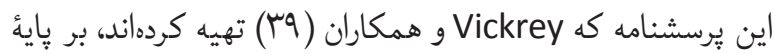

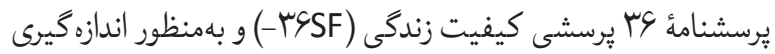
كيفيت زندكى بيماران مبتلا به MS طراحى شده است. اين برسشنامه 
مبتلابه MS از تحليل كواريانس استفاده شد. به اين ترتيب كه براى كاى كاي مقايسةٔ دو كروه آزمايش و كنترل در متغير كلى كيفيت زندكى از تحليل كوواريانس تكمتغيرى (Ancova) و براى مقايسةٔ مؤلفههاى كيفيت زندگى از تحليل كوواريانس جندمتغيرى (Mancova)

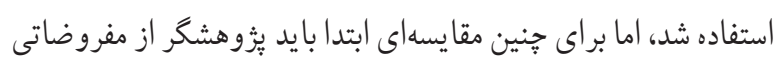

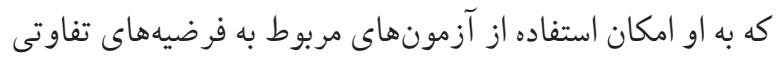

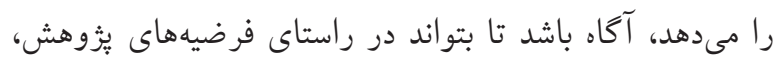

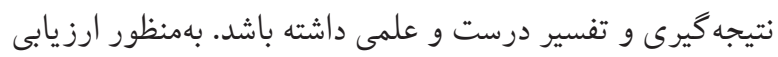

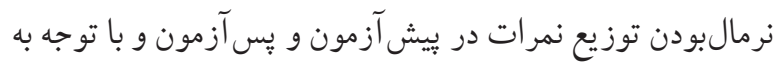
اينكه تعداد كروهها كمتر از • له آزمودنى است، از آزمون - shapio

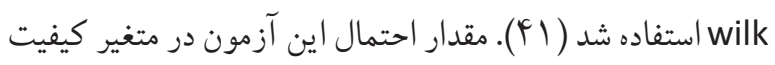
زندگى و مؤلفههاي سلامت جسمى و سلامت ذهنى در بيش آزمون

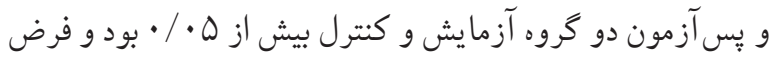

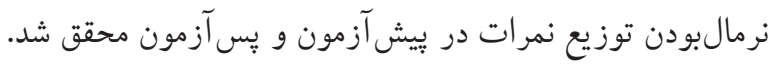

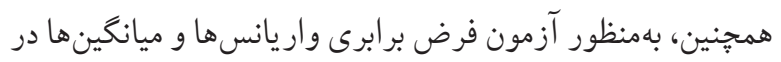

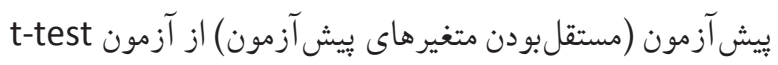

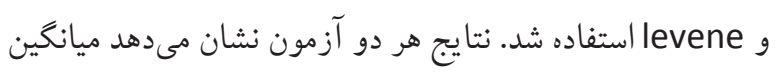

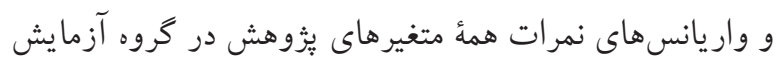

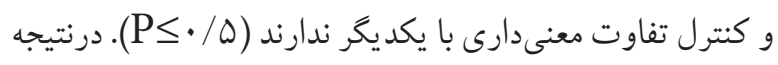

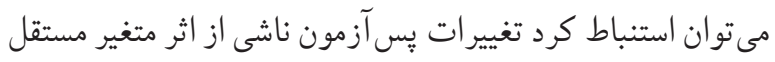

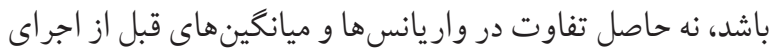

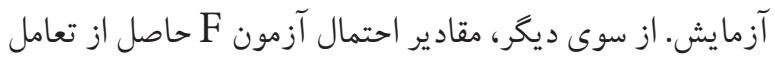

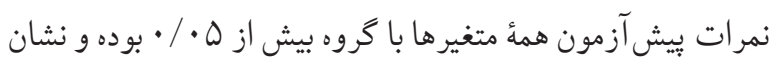
داد مفروضه همخنى شيبهاى ركرسيون درمورد متغير كيفيت

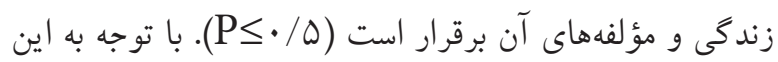
نتايج، استفاده از روش تحليل كوواريانس بلامانع است.

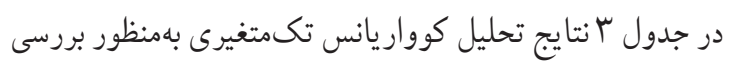
تأثير ACT بر كيفيت زندگى بيماران مبتلا به MS در كروههاى

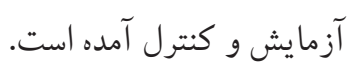

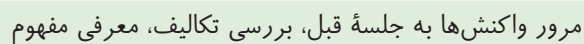

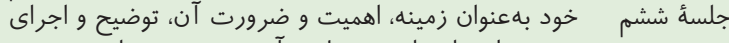
استعار ههاى مربوط به آن، جمع بندى جلسه آنه توضيح

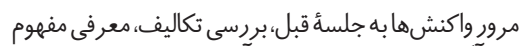

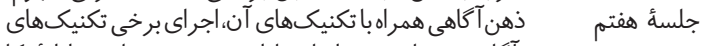

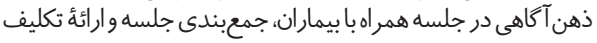

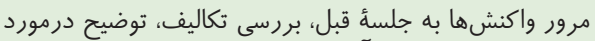

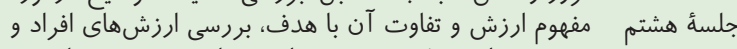

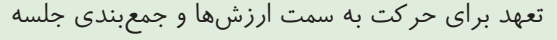

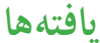

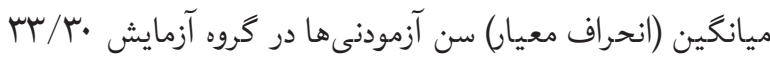

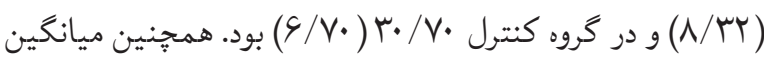

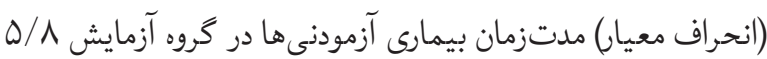

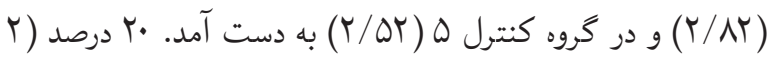
نف) از آزمودنىها هر دو گروه را زنان و •م دروصد را مردان تشكيل

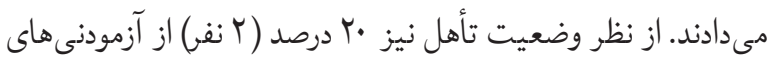

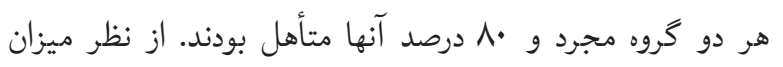

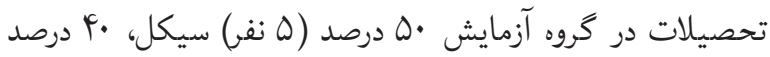
(أنف) دييلم و •ا درصد ( ا نفر) ليسانس داشتند. در كروه كنترل

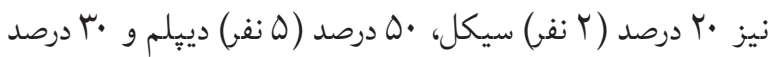

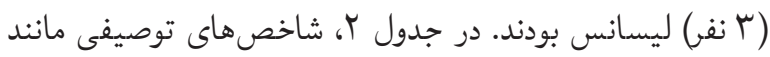

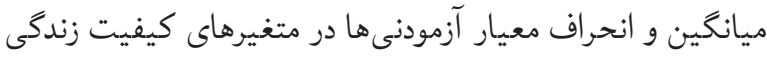

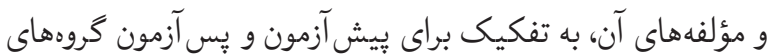
آزمايش و كنترل آمده است.

جدول r. شاخصهاى توصيفى متغير كيفيت زندگى و مؤلفههاى آن

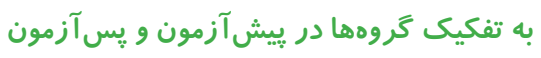

\begin{tabular}{|c|c|c|c|c|c|}
\hline \multirow{2}{*}{\multicolumn{2}{|c|}{ ميانغين إستاندارد }} & \multicolumn{2}{|c|}{ بيش آزمون } & \multirow[b]{2}{*}{ كروه } & \multirow[b]{2}{*}{ متغير } \\
\hline & & استاندارد انحراف & ميانكين & & \\
\hline$r \Lambda / \cdot q$ & $19 \cdot / 40$ & $r q / 11$ & $1 \cdot F / \& V$ & آزمايش & \multirow{2}{*}{ كيفيت زندگى } \\
\hline$r q / / f$ & $111 / 9$. & $r \cdot / v r$ & $\mid r F / r q$ & كنترل & \\
\hline $\mid r / r V$ & $V \cdot / 4$. & $10 / 11$ & $19 / 1 / 9$ & آزمايش & \multirow{2}{*}{ سلامت جسمى } \\
\hline$r \cdot / \mu_{q}$ & $\Delta S / V \Psi$ & $r M / \cdot V$ & 4.11. & كنترل & \\
\hline $19 / 94$ & $19 / 4 F$ & $10 / 40$ & $\Delta r / V \Lambda$ & آزمايش & سلامت ذهنى \\
\hline
\end{tabular}

بهنظور بررسى معنىدارى ACT بر بهبود كيفيت زندكى بيماران 
جدول ه. نتايج تحليل كوواريانس جندمتغيرى مؤلفههاى سلامت جسمى و ذهنى در كروههاى آزمايش و كنترل

\begin{tabular}{|c|c|c|c|c|c|c|c|}
\hline ضر اتب & مقدار & F & مجذوراتخين & آزادى درجة & مجذورات & & متغير \\
\hline سش/. &.$/ \cdot 1$ & $V / 9 r$ & $\wedge ৭ \vee / \wedge \Delta$ & 1 & $\wedge ৭ \vee / \wedge \Delta$ & آزيش & \\
\hline$\cdot / \Delta F$ &.$/ \cdots 1$ & IN/VD & rITE/.I & 1 & r|rs/. & مدراخلة & سلامت \\
\hline - & - & - & $\| \mu / \mu r$ & 19 & $|\wedge| r / \Delta \mid$ & خطا & \\
\hline . $/ \Delta r$ &.$/ \cdots 1$ & $I V / F T$ & rOTA/DG & 1 & TOTN/OG & آزيشن & \\
\hline$\cdot 199$ &.$/ \cdot$ & $\mathrm{rV} / \cdot \Lambda$ & $\Delta$ UVA $/ . .1$ & 1 & $\Delta r V \lambda / \cdots 1$ & مدروهلة & ذهلامت \\
\hline- & - & - & $\mid F \Delta / \cdot 1$ & 19 & זr/. זrז & خطا & \\
\hline
\end{tabular}

با توجه به جدول ه، ACT تأثير معنىدارى بر بهبود مؤلفهُ سلامت

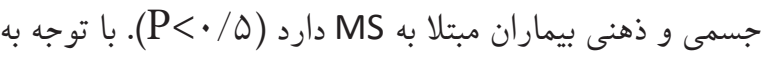

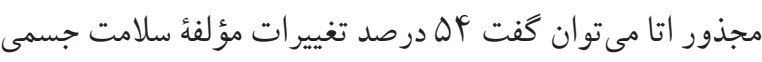

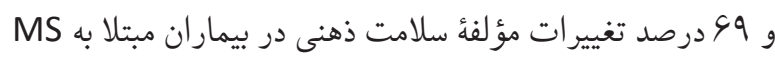
ناشى از تأثير ACT (A و است.

يُزوهش حاضر با هدف تعيين تأثير ACT بر بهبود كيفيت زندكى

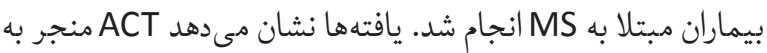
بهبود كيفيت زندگى و مؤلفههاى سلامت جسمى و ذهنى بيماران

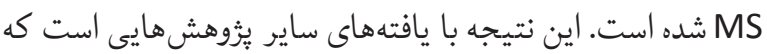

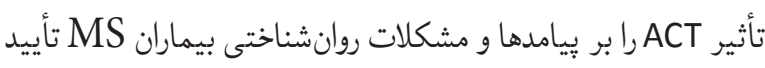
كردهاند همسوست. از جمله نتايج يثوهش Sheydayi Aghdam

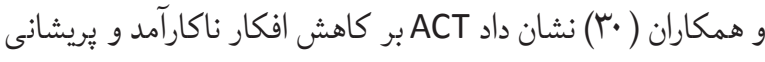
بيماران مبتلابه MS مؤثر است. براساس يزوهشى ديخر نيز، ACT بر اضطراب و افسردگى بيماران مبتلا به MS مؤثر است (آ⿱一). همجنين براساس ساير مطالعاتى كه به بررسى تأثير ACT بر ابعاد

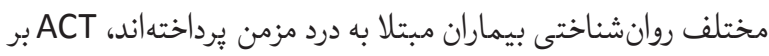

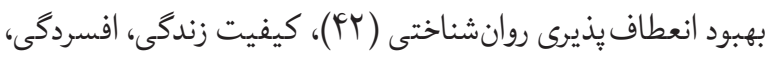

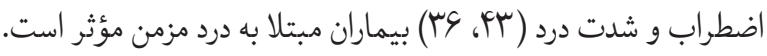

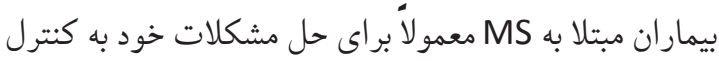

جدول س. نتايج تحليل كوواريانس تكمتغيرى بهمنظور بررسى تأثير

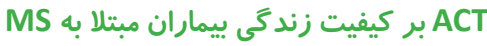

\begin{tabular}{|c|c|c|c|c|c|c|}
\hline ضر يب & مقدار & F & مجذانغين & درآزئ & مجذورات مجموع & \\
\hline.$|9|$ &.$/ \cdot 1$ & rs/19 & IrVq9/9F & 1 & $1 r V q q / q r$ & يِش آزمون \\
\hline$\cdot / g F$ &.$/ \cdot \cdot 1$ & $r \cdot / \Delta F$ & IFOHN/rT & 1 & IFOHN/rT & مداخلة گروه \\
\hline- & - & - & FVD/QF & IV & $1 \cdot 9 \cdot / 91$ & خطا \\
\hline
\end{tabular}

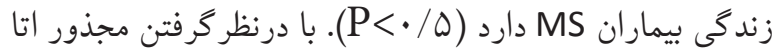

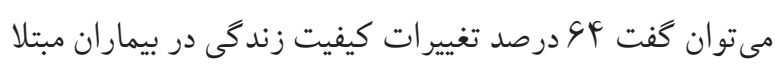

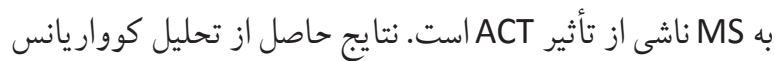

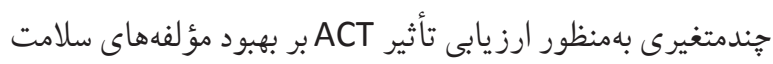
جسمى و ذهنى در جدول F آمده است.

جدول عا. نتايج آزمون جندمتغيرى بهمنظور بررسى تأثير ACT بر

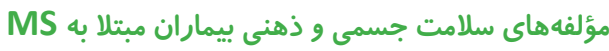

\begin{tabular}{|c|c|c|c|c|c|c|}
\hline ضريب & مقدار & خراى درأ & فرضأ درضيه & f & مقدار & گروه \\
\hline$\cdot / V 1$ &.$/$ & 10 & $r$ & $1 \wedge / 94$ & $\cdot / V 1$ & يِيلايى تريسى \\
\hline$\cdot / V 1$ &.$/$ & 10 & $r$ & $\mid 1 / 94$ & $\cdot / r \wedge$ & لامبداى ويلكز \\
\hline$\cdot / V I$ &.$/$ & 10 & r & $1 N / 94$ & $r / \Delta r$ & اثر هتلينگ \\
\hline$\cdot / V 1$ &.$/$. & 10 & r & 11/94 & $r / \Delta r$ & بزرقترين ريشه \\
\hline
\end{tabular}

بر اساس نتايج جدول أ، هر جهار آزمون حاكى از تأثير ACT

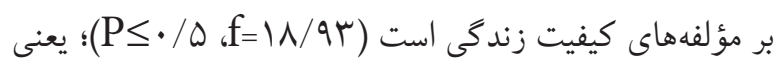

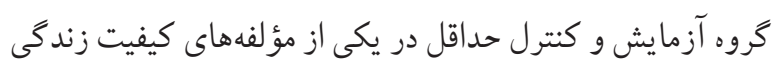
تفاوت معنى دارى دارند. بهمنظور آكاهى از معنى دارى و مقدار تأثير ACT

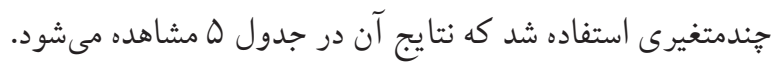


و موجوديت فرد را تحقير نمى كند، موجب مىشود فرد احساس

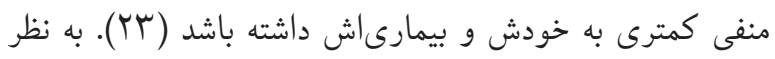

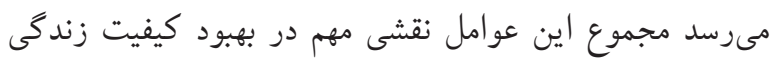

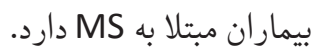
از سوى ديكر، به اين دليل كه افراد مبتلا به MS با افكار خود دارد

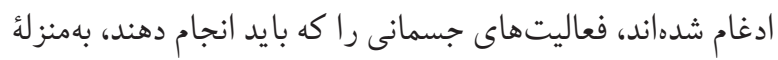
محركى نفرتانكيز تفسير و كمان مى كنند انجامدادن اين فعاليتها سبب ايجاد يا افزايش مشكلات جسمانى مىشود و كاهش فعاليت

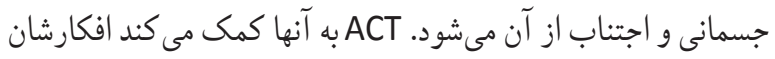

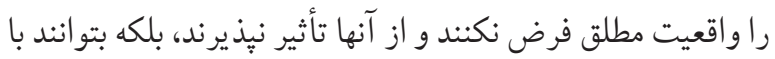

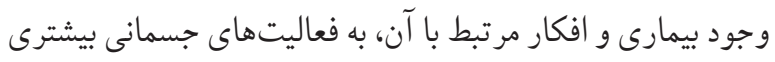

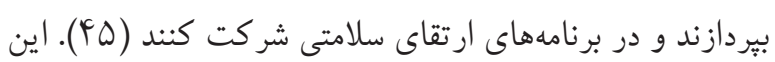
فعاليتهاى مناسب موجب نشاط جسمى بيشتر و درنتيجه بهبود

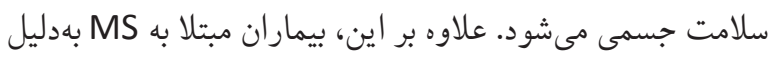

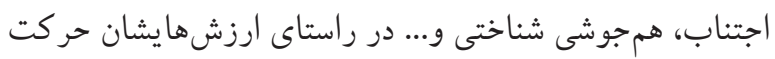
نمى كنند. اين درمان ارزشها را بهعنوان كيفيت انتخابش ونده اعمال

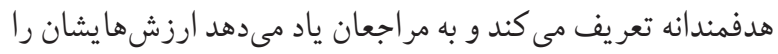

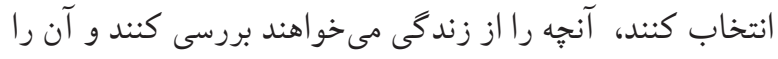

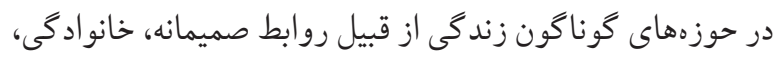
شغلى و... مدنظر قرار دهند. برخى ابعاد كيفيت زندگى در حر جلسات

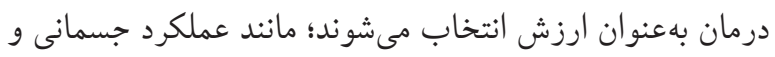

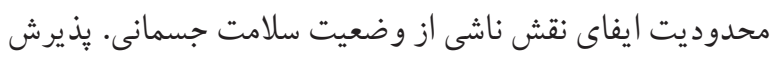

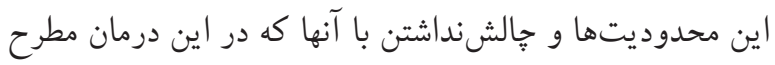

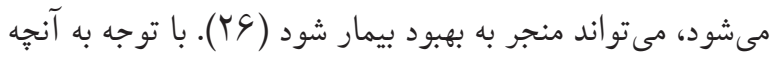
بيان شد، اين عوامل ممكن است در بهبود سلامت جسمى بيماران

مؤثر باشد.

به بيمار ان كمك مى كند خودشان را از تجارب ذهنىشان جدا

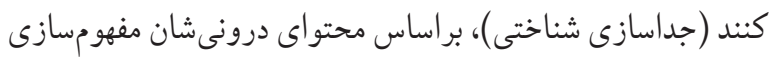
نكنند و خود را بافتارى در نظر بحيرند كه افكار، احساسات و حواس

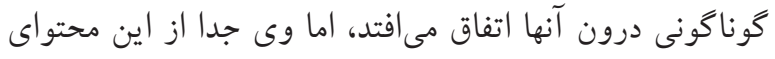
درونى است و تنها آنها را نظاره مى كند، بدون اينكه عكس العملى دونى
و اجتناب روى مى آورند.ACT به فرد كمك مى كند تا ابتدا سيستم كنترل - اجتنابى خود در زندگى را استخراج كند. سيس فرد به اين نتيجه مىرسد راهحل هايى كه تاكنون استفاده كرده است (كنترل و جتناب) مفيد نبودهو بهويزه در درازمدت كمكى نكرده است؛ زيرا

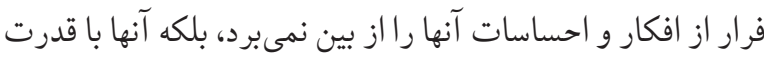

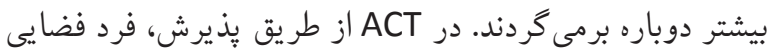

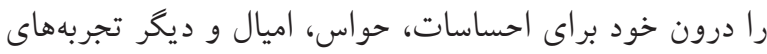

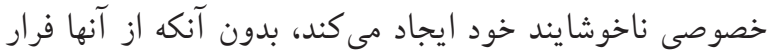
كند. همجنين به بيماران كمك مى شود بيمارى را جزئى از زندكى

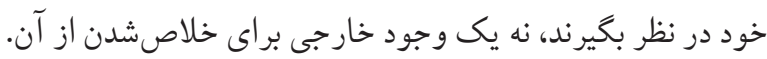

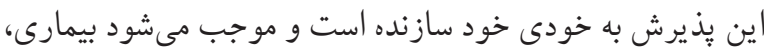

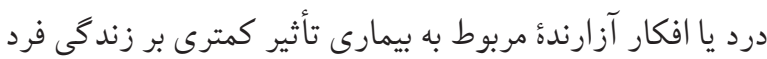

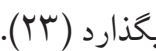

از سوى ديخر، ACT و اقعيت افكار فرد را به جالش مى كشد و آنها را تحقير مى كند. بيمار ان در نتيجةُ بيمارى معمولاً افكار منفى دئى

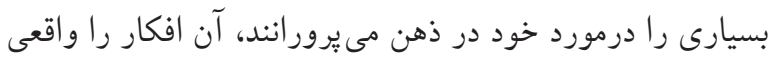

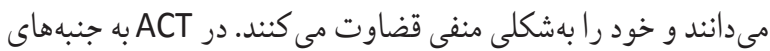

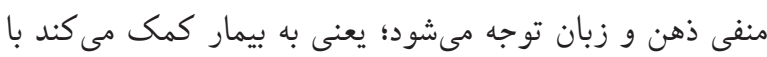

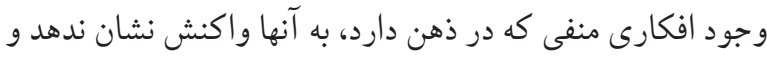

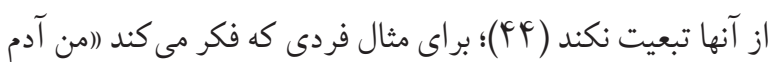
ضعيفى هستم) سعى كند اين فكر دجار كوشهنشينى و اجتناب از

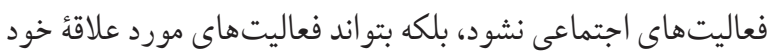
را انجام دهد. جدى و واقعى فرضنكردن افكار (كسلششناختى)

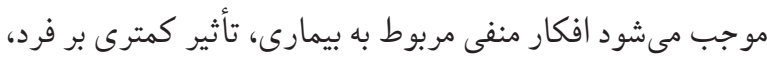

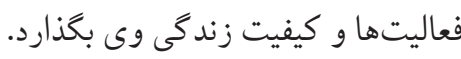

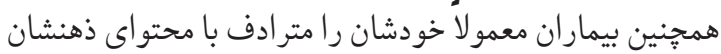
در نظر مى گيرند و خودشان را براساس آن تعريف مى كنند؛ براى

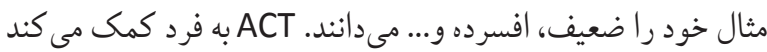
بهجاى آن، خود را زمينه در نظر بكيرد؛ يعنى بهجاى اينكه بكويد

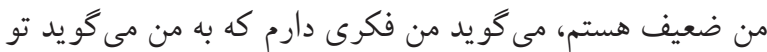

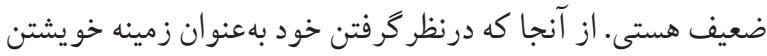


وجود بيمارى و درد ناشى از آن مشكلات ذهنى و جسمى كمترى را تجربه كنند و كيفيت زندگى خود را بهبود بخشند. بيشنهاد مى شود درد

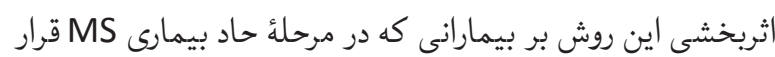
دارند نيز بررسى شود. همجنين بهتر است با روش هاى درمانى ديكر بهر

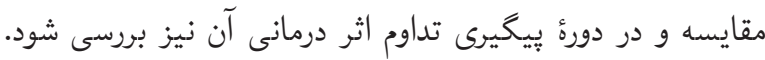

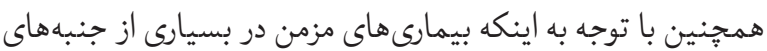
روانشناختى و برخى جنبه هاى جسمانى مشكلات تقريباً مشابهى

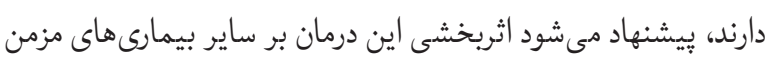

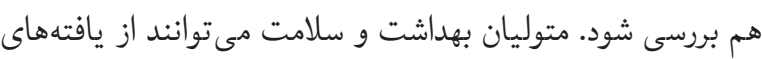

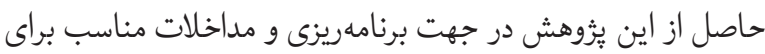

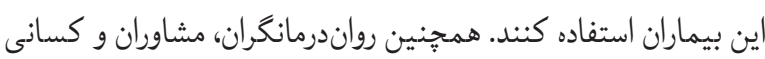

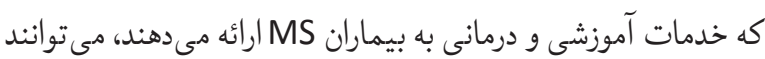
از درمان ACT براى كمك به بهبود كيفيت زندگى بيماران بهان بهره

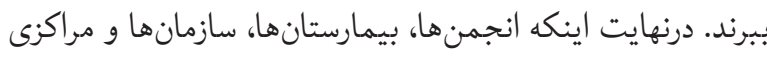

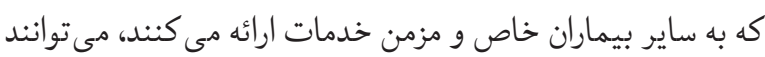
از درمان ACT براى كمك به بهبود كيفيت زندگى آن بيماران در كنار ساير برنامههاى مداخلهاى استفاده كنند.

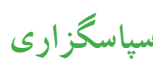
مقالة حاضر بركرفته از پاياننامهُ كارشناسى ارشد رشته مشاورهُ دانشگاه بجنورد است كه با كد ..با||سا به تصويب شوراى تحصيلات تكميلى دانشگاه رسيده است. بدينوسيله از همهُ شركت كنندگان

$$
\begin{aligned}
& \text { يُّوهش تشكر و قدردانى مىشود. } \\
& \text { تعارض در منافع }
\end{aligned}
$$

ميان نويسندگان هيج تعارضى در منافع گزارش نشده است.

\section{References}

1. Jafari $Y$, Vahedian-Shahroodi $M$, Tehrani $H$, Esmaily $H$, Haresabadi M, Shariati $M$. The relationship between caregivers' health literacy and the behavior of women with Multiple Sclerosis. The Iranian Journal of Obstetrics, Gynecology and Infertility. 2018;21(7):64-71.2.

3. Albuquerque C, Geraldo A, Martins R, Ribeiro O, Quality of life of people with multiple sclerosis: clinical and psychosocial determinants. Procedia - Soc Behav Sci. 2015:171:359-365.

https://www.sciencedirect.com/
نشان دهد. به عبارت ديخر ACT سعى مى كند از طر يق عينىسازى

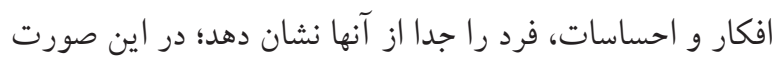
فرد بهجاى خودش، افكار و احساساتش را مشكلزا مىداند و اين موجب مىشود آن محتو اهاى درونى ناخوشايند كمتر بر بيماران

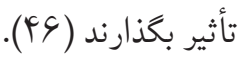

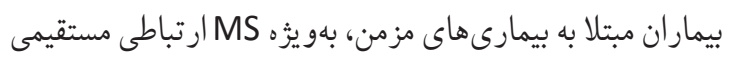

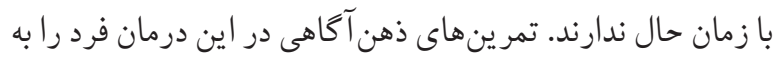

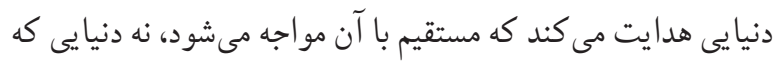

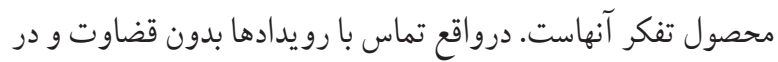

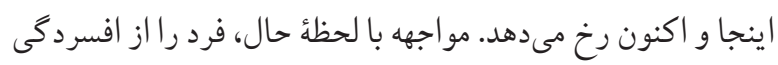

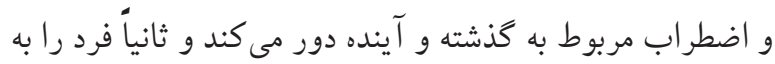

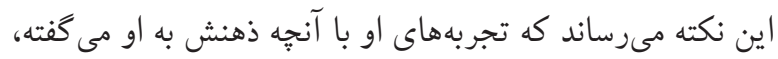
متفاوت است. به عبارت ديكر، تمر ينهاي ذهن آكاهى سبب تسهيل

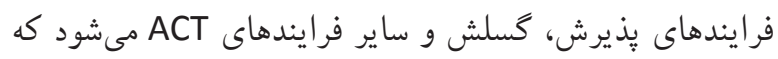

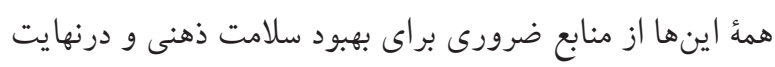

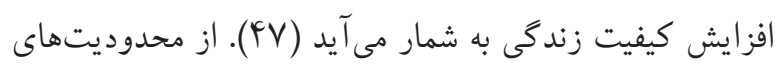
يُزو هش حاضر مى توان به شيوهُ نمونه گيرى غير تصادفى، نبود مر حله

$$
\text { يّيخيرى و كوجى بودن نمونهُ مورد بررسى اشاره كرد. }
$$
نتيجاه كيرى كيفيت زندكى در بيماران مبتلا به MS دجار افت شديدى مى شودو و بر سلامت جسمى و ذهنى آنها تأثير مى گذارد. در اين زمان، بيماران معمولاً براى كاهش مشكلات ذهنى و جسمى، به اجتناب و كنترل افكار، احساسات، خاطرات و حس هاى بدنى آزاردهنده خود روى مى آورند، اما اين تلاشها كارساز نيست يا تنها در كوتاهمدت مؤثر است، اما در درازمدت، آن افكار، احساسات و حس هاى ناخوشايند بازمى گردد. در حنين شرايطى، ACT به فرد كمك مى كند تا راهبردهاى غيرمؤثر

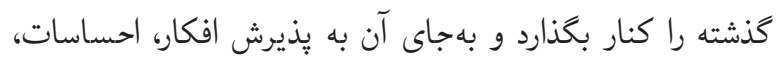

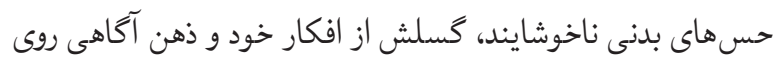

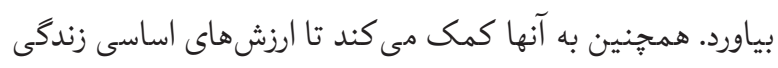

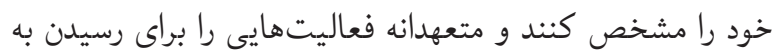

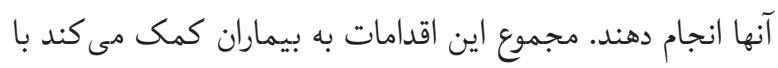


science/article/pii/S1877042815001639

4. Demaille-Wlodyka S, Donze C, Givron P, Gallien P, A review of psychological correlates of adjustment in patients with multiple sclerosis. Ann Phys Rehabil Med 2011:54: 109128. https://www.sciencedirect.com/science/article/pii/ S1877065711000042

5. Roudbari SA, Ansar MM, Yousefzad A, Smoking as a risk factor for development of secondary progressive multiple sclerosis: a study in iran, guilan. J Neurol Sci. 2013:330:5255. https://www.sciencedirect.com/science/article/abs/ pii/S0022510X13001652

6. Sharifi Neyestanak ND, Ghodoosi Boroojeni M, Seyedfatemi N, Heydari M, Hoseini AF. Self Esteem and its Associated Factors in Patients with Multiple Sclerosis. Iran Journal of Nursing (2008-5923). 2012 Nov 1;25(78).

7. Bethoux F, Bennett S. Evaluating walking in patients with multiple sclerosis: which assessment tools are useful in clinical practice?. International journal of MS care. 2011 Mar;13(1):4-14.

8. Taraghi Z, Ilali E. Quality of life among multiple sclerosis patients. J Applied Sci. 2010 Dec;10(14):1485-8.

9. MCcabe MP. Mood and self-esteem of persons with multiple sclerosis following an exacerbation. Journal of psychosomatic research. 2005 Sep 1;59(3):161-6.

10. Janardhan V, Bakshi R. Quality of life in patients with multiple sclerosis: the impact of fatigue and depression. Journal of the neurological sciences. 2002 Dec 15;205(1):51-8.

11. Morgante L. Hope in multiple sclerosis: a nursing perspective. International Journal of MS Care. 2000 Jun;2(2):9-15.

12. Bonomi AE, Patrick DL, Bushnell DM, Martin M. Validation of the United States' version of the world health organization quality of life (WHOQOL) instrument. Journal of clinical epidemiology. 2000 Jan 1;53(1):1-2.

13. Hadgkiss EJ, Jelinek GA, Weiland TJ, Rumbold G, Mackinlay CA, Gutbrod S, Gawler I. Health-related quality of life outcomes at 1 and 5 years after a residential retreat promoting lifestyle modification for people with multiple sclerosis. Neurological Sciences. 2013 Feb 1;34(2):187-95.

14. Gedik Z, Sorias O, Idiman E. Do coping styles mediate the relationship between disability status and psychosocial loss in people with relapsing remitting multiple sclerosis?. Journal of health psychology. 2017 May;22(6):707-21.

15. Klevan G, Jacobsen CO, Aarseth JH, Myhr KM, Nyland H, Glad S, Lode K, Figved N, Larsen JP, Farbu E. Health related quality of life in patients recently diagnosed with multiple sclerosis. Acta Neurologica Scandinavica. 2014 Jan;129(1):21-6.
16. Senders A, Sando K, Wahbeh H, Peterson Hiller A, Shinto $\mathrm{L}$. Managing psychological stress in the multiple sclerosis medical visit: Patient perspectives and unmet needs. Journal of health psychology. 2016 Aug;21(8):1676-87.

17. Mitchell AJ, Benito-León J, González JM, Rivera-Navarro J. Quality of life and its assessment in multiple sclerosis: integrating physical and psychological components of wellbeing. The Lancet Neurology. 2005 Sep 1;4(9):556-66.

18. Dennison L, Moss-Morris R, Chalder T. A review of psychological correlates of adjustment in patients with multiple sclerosis. Clinical psychology review. 2009 Mar 1;29(2):141-53.

19. Rasooli M, Bahramian J, Zahrakar K, The effectiveness of hope therapy to group style on quality of life dimention among MS patiens. J Family Health. 2014:3(1):1-11. (Persian). http://ijpn.ir/article-1-243-fa.html

20. Mardanivalendani M, Ghafari Z, The effectiveness of logotherapy on quality of life among MS patients in shahrekord. Sci J Ilam Univ Med Sci. 2014:23(5). (Persian).

21. Saeedi $H$, Musavinasab MH, Mehdizade A, Ebrahimi HA, Gorganinejad M, Divsalar K, The effectiveness of positive psychology intervention fit Islamic approach on quality of life and hope in multiple sclerosis females in kerman city, National conference First of Psychology. Educational Science and Social Pathology. 2015. (Persian).

22. Soleimani E, Habibi M, Basharpuor S. Effectiveness of selfcontrol training on dimensions of quality of life in multiple sclerosis patients. Journal of Research Behavior Science. 2013;10(7):746-56.

23. Strosahl K, Wilson KG. Acceptance and commitment therapy: an experiential approach to behavior change. new york.

24. Fung K. Acceptance and commitment therapy: Western adoption of Buddhist tenets?. Transcultural Psychiatry. 2015 Aug;52(4):561-76.

25. Hayes SC, Masuda A, Bissett R, Luoma J, Guerrero LF. DBT, FAP, and ACT: How empirically oriented are the new behavior therapy technologies?. Behavior Therapy. 2004 Dec 1;35(1):35-54.

26. Hayes SC, Pistorello J, Levin ME. Acceptance and commitment therapy as a unified model of behavior change. The Counseling Psychologist. 2012 Oct;40(7):9761002.

27. Roditi D, Robinson ME. The role of psychological interventions in the management of patients with chronic pain. Psychology research and behavior management. 2011;4:41.

28. Izadi R, Abedi MR, Acceptance and commitment therapy. Tehran: Jungle, 2012 (Persian). 
29. Hayes SC, Levin ME, Plumb-Vilardaga J, Villatte JL, Pistorello J. Acceptance and commitment therapy and contextual behavioral science: Examining the progress of a distinctive model of behavioral and cognitive therapy. Behavior therapy. 2013 Jun 1;44(2):180-98.

30. Sheydayi Aghdam S, Shamseddini lory S, Abassi S, Yosefi S, Abdollahi S, Moradi joo M. The effectiveness of treatment based on acceptance and commitment in reducing distress and inefficient attitudes in patients with MS. Thoughts and behavior in clinical psychology. 2015:9(34): 57-66. (Persian). http://jtbcp.riau.ac.ir/article_108.html

31. Rajabi S, F Yazdkhasti S. The Effectiveness of Acceptance and Commitment Group Therapy on Anxiety and Depression in Women with MS Who Were Referred to the MS Association. Journal of clinical psychology, 2014:6(1): 29-38. (Persian).

32. Hayes SC, Bissett RT, Korn Z, Zettle RD, Rosenfarb IS, Cooper LD, Grundt AM. The impact of acceptance versus control rationales on pain tolerance. The psychological record. 1999 Jan 1;49(1):33-47.

33. McCracken LM, Gauntlett-Gilbert J, Eccleston C. Acceptance of pain in adolescents with chronic pain: Validation of an adapted assessment instrument and preliminary correlation analyses. European Journal of Pain. 2010 Mar;14(3):316-20.

34. McCracken LM, Zhao-O'Brien J. General psychological acceptance and chronic pain: There is more to accept than the pain itself. European Journal of Pain. 2010 Feb;14(2):170-5.

35. Johnston M, Foster M, Shennan J, Starkey NJ, Johnson A. The effectiveness of an acceptance and commitment therapy self-help intervention for chronic pain. The Clinical journal of pain. 2010 Jun 1;26(5):393-402.

36. Wicksell RK, Ahlqvist J, Bring A, Melin L, Olsson GL. Can exposure and acceptance strategies improve functioning and life satisfaction in people with chronic pain and whiplash-associated disorders (WAD)? A randomized controlled trial. Cognitive behaviour therapy. 2008 Sep 1;37(3):169-82.
37. Vowles KE, McCracken LM. Acceptance and values-based action in chronic pain: a study of treatment effectiveness and process. Journal of consulting and clinical psychology. 2008 Jun;76(3):397.

38. Mason VL, Mathias B, Skevington SM. Accepting low back pain: is it related to a good quality of life?. The Clinical journal of pain. 2008 Jan 1;24(1):22-9.

39. Vickrey B, Hays RD, Harooni R, Myers LW, Ellison GW. A health-related quality of life measure for multiple sclerosis. Quality of life research. 1995 Jun 1;4(3):187-206.

40. Ghaem $H$, Haghighi AB, Jafari P, Nikseresht AR. Validity and reliability of the Persian version of the Multiple Sclerosis Quality of Life questionnaire. Neurology India. 2007 Oct 1;55(4):369.

41. Tabachnick BG, Fidell LS. Using multivariate statistics, 6th edn Boston. Ma: Pearson. 2013. Scott W, McCracken LM. Psychological flexibility, acceptance and commitment therapy, and chronic pain. Current Opinion in Psychology. 2015 Apr 1;2:91-6.

42. Wicksell RK, Olsson GL, Hayes SC. Mediators of change in acceptance and commitment therapy for pediatric chronic pain. Pain. 2011 Dec 1;152(12):2792-801.

43. Flaxman PE, Blackledge JT, Bond FW, Acceptance and commitment therapy: distinstive features, Translated by Mosleh Mirzaei, Saman Noonahal. Tehran: Arjmand, 2012.

44. Verbunt JA, Seelen HA, Vlaeyen JW, van de Heijden GJ, Heuts PH, Pons K, Knottnerus JA. Disuse and deconditioning in chronic low back pain: concepts and hypotheses on contributing mechanisms. European journal of pain. 2003 Feb;7(1):9-21.

45. Hayes SC. Acceptance and commitment therapy, relational frame theory, and the third wave of behavioral and cognitive therapies. Behavior therapy. 2004 Sep 1;35(4):639-65.

46. Brown KW, Ryan RM. The benefits of being present: mindfulness and its role in psychological well-being. Journal of personality and social psychology. 2003 Apr;84(4):822. 